"... a clumsy, half baked reaction dreamt up in spite and fury"

\title{
Debt collecting
}

The recent announcement that, on average, dentists in the UK now earn more than half their income from non-NHS work for the first time since the NHS began did not come as a particular surprise to many. The trend has been moving in that direction for some while now, accelerated no doubt by the imposition of the current NHS dental contract in April of last year.

That is to say it did not come as a surprise to most of us in the profession. Clearly though it did provide an unpalatable update for certain health service watchers including Keith Barron MP, chairman of the Common's Health Select Committee. In a statement he was quoted as saying that dentists had a 'moral obligation' to give the NHS more of their time; a sentiment which drew a swift response from BDA Chief Executive, Peter Ward.

In concert with this, Joyce Robbins, the co-director of Patient Concern called for quotas to be imposed on newly-qualified dentists to force them to spend a certain amount of time in the NHS - 'when people have been trained at enormous expense, they should give back some time to the NHS', she ventured.

It is the sort of knee-jerk reaction that we used to read in years gone by but not one that we expect nowadays. Let us first examine the words before we take a stab at understanding the sentiment behind them. Even if society did provide education 'free at the point of delivery' for dental students, rather than requiring them to pay a substantial portion of the costs, surely the requirement to repay society would be incumbent on all university students to do the same? So geography students would spend the appropriate number of hours drawing maps or whatever it is geography students learn for the greater benefit of society. Perhaps we could call them UDAs - Units of Debt Activity.

Of course it makes no sense. It's a silly notion because it is doubtless born out of spite and possibly anger and maybe even some envy. Understandable perhaps, as it was the government of which Mr Barron is so vociferously a part that sought to impose the new arrangements rather than seek the advice of the dental profession, the people who knew and who are now expected to attempt to make them work.

However, while we might smile at the naivety there is a rather more serious and sinister sentiment that lurks behind such thinking. For a number of years now the media in general have responded to stories about lack of NHS dental care and dentists moving to private practising arrangements with very positive support for the profession. The tenor of reportage and editorial comment has been along the lines that state funding has been insufficient to allow dental care to be provided at standards acceptable to the profession and consequently for patients.

Previously it was not so. Those of us with longer memories will recall the 'greedy rich dentists' approach by media items of this sort. Having closely attended to this aspect of our professional lives for some few years now, it is my belief that the Press and Parliamentary staff at the BDA have been, and continue to be, a major, positive influence on this. It has been their steady, consistent and persistent work that turned the tide and guided journalists into perceiving the situation through the eyes of the profession.

So, is this perception changing back again? Has last year's contract change somehow shifted this balance again? It is too early to say for sure. This outburst may be a one off, a loose cannon spurred into motion by a sectional interest. However, we should remain watchful. As well as the BDA, we can all play our part in continuing to clearly explain the treatment benefits that we are each able to provide to our patients under whichever system of remuneration we work. It is as important that we explain advantages as well as any shortcomings. Large companies spend huge sums in advertising to reassure their existing customers that have made the 'right' choice in investing in their products and services so as to ensure that they continue their loyalty. Since we are now earning more than half our incomes from the non-NHS area it also means that more and more patients are being treated under private arrangements, providing us with the opportunity to continue to explain our philosophies and to reinforce the value of our services.

However much Mr Barron may wish that things were different, they are as they are, and the trend suggests more of the same. Gone are the days of the seemingly endless trail of oral disease that needed 'fixing' and which would be paid for by the State. In its place is a world in which we have to adjust not only our aspirations, our standards and our services but also our need to explain and provide justification for our beliefs in what we do. If there is a debt that we owe our patients, which in any case I think might be more elegantly and accurately described as a duty, then this is what it consists of and not a clumsy, half baked reaction dreamt up in spite and fury.

Stephen Hancocks OBE Editor-in-Chief

DOI: $10.1038 /$ bdj.2007.655 